\title{
Design and Implementation of Personalized Network Teaching Management System Based On the JSP
}

\author{
Guangyu Wang ${ }^{1, \text { a }}$, Jing Zhang ${ }^{2, \mathrm{~b}}$, Dan $\mathrm{Han}^{3, \mathrm{c}}$ \\ 1,2,3 Department of Computer, Aviation university of Air Force, Changchun, 130000, China \\ aemail: 1803097835@qq.com, bemail:524402684@qq.com, email: 87939060@qq.com
}

Keywords: JSP; Personalized Network Teaching; Data Mining

\begin{abstract}
Along with the development of information technology, the network education is rising and the online courses are innovating. But the information of network resources is so huge, that it is too difficult to distinguish between good and bad. The students spend a lot of time to find the information they need, but not necessarily be able to find it. In this paper, according to their relevant information, JSP and data mining are applied to designing the network teaching resource module. It can provide the learning resources the students need and improve their learning efficiency.
\end{abstract}

\section{Introduction}

In the 21st century, with the rapid development of information technology, an unprecedented challenge is putting forward in education. The network teaching model as a new educational has been more and more applications in the actual teaching activities. So many universities have built the network teaching system actively, to create the open education and students' active learning environment. Although the technical means of the network course has been very mature, there are many deficiencies in the key of the design, influence network education of effect.

At present, the function of the network teaching system is so generalized and various that dispersing the students' attention and leading to teaching resources dispersed. Although collecting many learning resources in the system, there are not the personalized recommendation and retrieval system that waste a lot of time and affect the enthusiasm of students' learning. So, we should effectively integrate and optimize network system resources based on the students' learning goals and interest, to provide network teaching resources their needs and establish a fast and accurate retrieval module.

\section{System Development Tools}

\section{JSP}

JSP (Java Server Pages) is form Sun Microsystems advocated, many companies were involved in the establishment of a dynamic web technology standards, recognized by the whole world. JSP technology using Java language as a scripting language provides an interface to the HTTP service in the application procedures [1]. JSP pages develop and produce static and dynamic content, this page layout and style alone editing and debugging without affecting the dynamic content generation. Components can improve the code repetition utilization, to improve the efficiency of the development of Web applications. After Web service receives the access request, through its attached code execution, according to the code needs to return the data, and sends the HTML code and the result to the client.

\section{DBMS}

Without data we have no way of management, it is the soul of the system. For the development of the system, the choice of database is very important. Here I choose economic and efficient MySQL[2]. MySQL is a small relational database management system, and is an open source database. SQL (Structured Query Language) is a database language having powerful function, used for database communications. Its outstanding advantages are non-procedural, unity, and are the common language for all relational databases.

The basic system model is shown in Figure 1. 


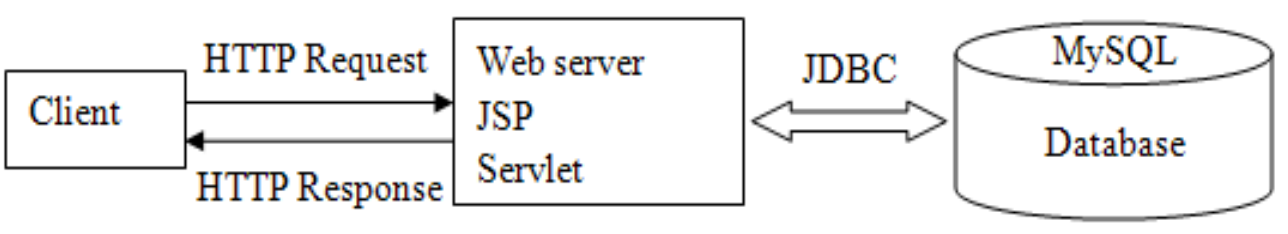

Fig.1. The basic system model.

\section{Module Design}

According to the results of the system needs and combing with practical application, the network teaching system is divided into four modules, which are resource management, bulletin management, user management and online courses, as shown in Figure 2.

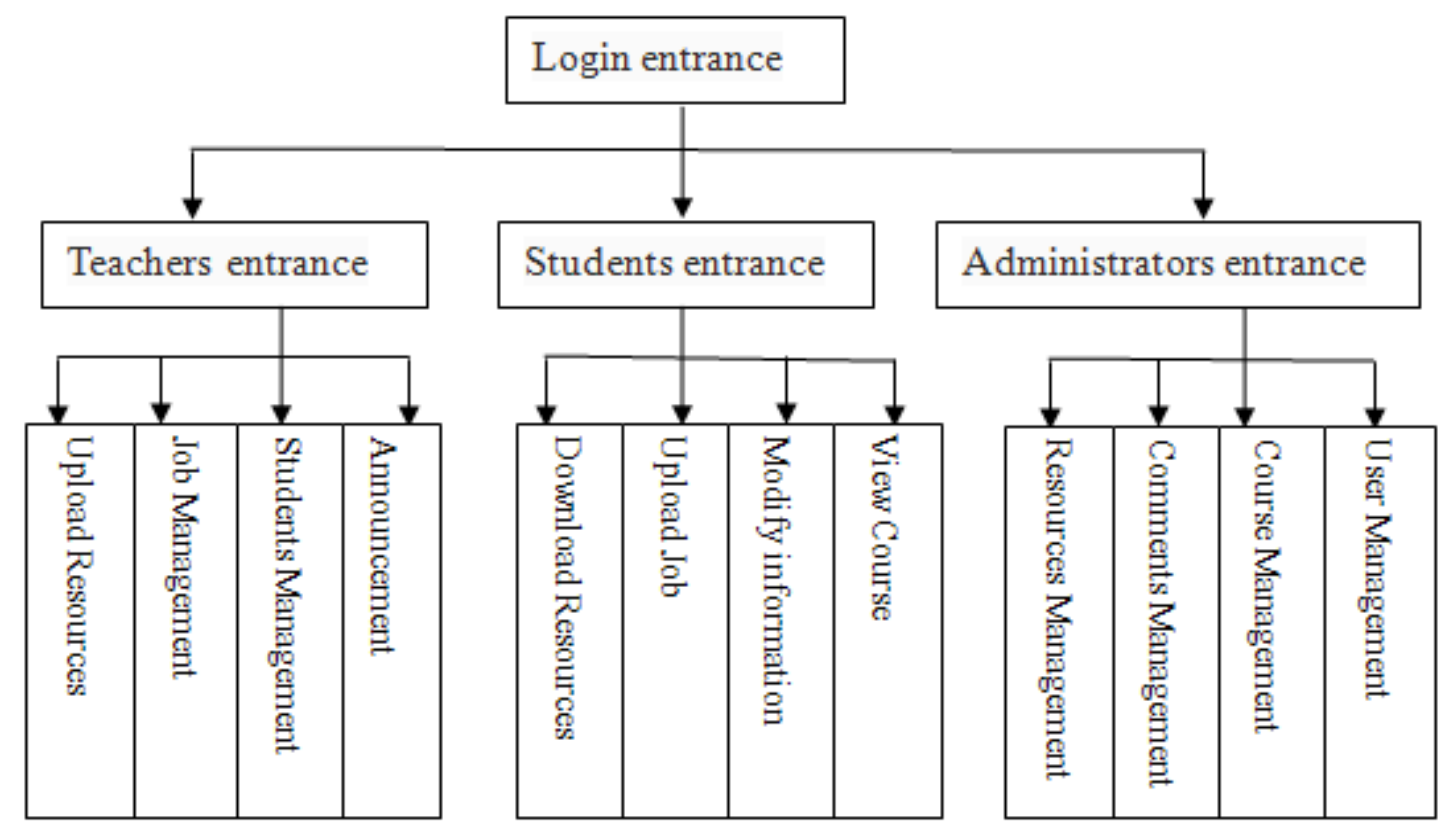

Fig.2. The system function module

1) Resource management module: according to their competence, users can share resources, upload and download, to facilitate teaching.

2) Bulletin management module: delete and announcement.

3) User management module: the administrators can delete and add users; they control users' operating authority.

4) Online courses module: add majors and courses, view the course information and submit the job.

This paper introduces the design the resource management module in the administrators' entrance.

\section{System implementation}

The system uses the popular JSP technology development Web application [3], the user interface are displayed by pages. In order to reflect the code portability better, the JSP / Servlet and Java Bean technology are used on the server side, and the Java Script language is used on the client side [4]. The system uses a database connection class for unified management of the database and encapsulates the database operations, to avoid loading every driver in front of database operations and creating a connection. 
The main purpose of table 1 is to store resource information, including uploading the author, resource belongs curriculum, resource description, resource size, resource names.

Table.1. Resources table

\begin{tabular}{|c|c|c|c|c|c|}
\hline Name & Type & Length & Decimals & Allow Null & \\
\hline id & int & 10 & 0 & $\square$ & 8 \\
\hline title & varchar & 100 & 0 & $\checkmark$ & \\
\hline source_url & varchar & 255 & 0 & $\checkmark$ & \\
\hline date & varchar & 255 & 0 & $v$ & \\
\hline user_id & int & 20 & 0 & $\nabla$ & \\
\hline level & int & 10 & 0 & $\checkmark$ & \\
\hline introduction & varchar & 2000 & 0 & $v$ & \\
\hline source_name & varchar & 100 & 0 & $\nabla$ & \\
\hline course_id & int & 10 & 0 & $\checkmark$ & \\
\hline
\end{tabular}

In the teaching resource management module, the system adds the personalized teaching resources management module. It can be according to the characters of individual users in the repository for its accurate quickly provide search results, and recommend suitable learning resources. It consists of four sub-modules, which are data collection, data processing, data analysis and expression of results.

Teaching resource management is mainly to add, modify, delete, and query the teaching resources. The file name is resource.java, this file is used to describe the basic properties of teaching resources, as well as get and set methods of these property values. The code is as follow:

package grad.util.course;import java.util.*;

public class resourse \{

public resourse() \{

\}

int id=0;

String title="';

String course_id="';

String link="";

String ext="';

String filesize="';

String sdate=null;

int power=1;

\{

this.id=id;

\}

Public int getid()

\{

return this.id; $\cdots \cdots \cdots . . . . . .$.

At present, the information in the network teaching resources database is very massive. The key of the network teaching system is how to provide appropriate teaching resources and adopt different teaching strategies according to different users. Data mining can find potential associated information from each user so as to guide instructional decisions.

Here using Apriori, a mining association rules frequent itemsets mining algorithm to mining. Apriori algorithm is based on association rules of data mining algorithm, and is based on Boolean 
association algorithm for frequent item sets. The algorithm's mining process is divided into two main steps. First of all, it uses the candidate set for mining frequent itemsets, than produce association rules according to the frequent itemsets obtained. The results show that can effectively improve the level of personalized services network teaching system.

\section{Conclusion}

Relative to the closed traditional teaching mode, the information of network teaching is unimpeded. It breaks through the time, space, geographical restrictions, student-centered, individualized, to promote the cultivation of students' innovative consciousness and innovative ability. The function of the system is currently relatively simple, but practical practicality and flexibility. I will continue studying deeply, applying in practice and modifying the system according to the needs, so that it can improve the students' learning efficiency and the teachers' teaching quality, to satisfy the personalized needs of the teaching and learning process.

\section{References}

[1] Changlin Li. JSP dynamic web site set up the foundation and example operation. Electronic Industry Press. 2005.

[2] Baron Schwartz, Peter Zaitsev, Vadim Tkachenko. High Performance MySQL(Second Edition). Electronic Industry Press. 2010.

[3] Bryan Basham, Kathy Sierra, Bert Bates. Head First Servlets and JSP(Second Edition). China Electric Power Press. 2010.

[4] Liu Zhiyong. JavaScrip Development technology Daquan [M]. 1-5.Tsinghua University Press, Beijing, 2009.

[5] Jiawei Han, Micheling Kamber,Jian Pei. Data Mining Concepts and Techniques (Third Edition).Machinery Industry Press. 2012.

[6] Penelope Markellou, Loanna Mousourouli. Using semantic web mining technologies for personalized E-Learning experiences. Research Academic computer technology institute, 2004.

[7] Robert Sedgewick, Kevin Wayne. Algorithms (Fourth Edition). People Post Press, 2012. 